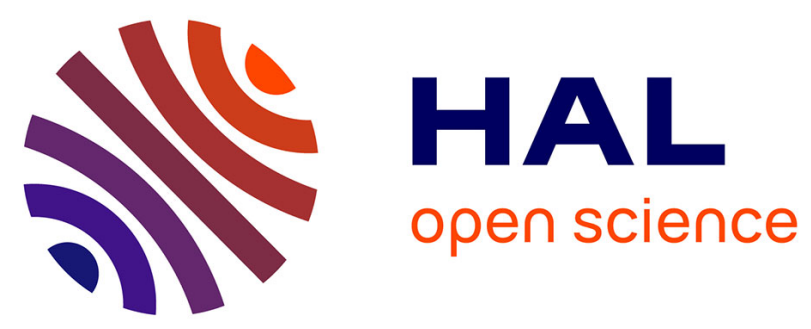

\title{
Competence Matching in Collaborative Consortia for Service-Enhanced Products
}

\author{
Ana Inês Oliveira, Mohammad Shafahi, Hamideh Afsarmanesh, Filipa \\ Ferrada, Luis M. Camarinha-Matos
}

\section{To cite this version:}

Ana Inês Oliveira, Mohammad Shafahi, Hamideh Afsarmanesh, Filipa Ferrada, Luis M. CamarinhaMatos. Competence Matching in Collaborative Consortia for Service-Enhanced Products. 17th Working Conference on Virtual Enterprises (PRO-VE), Oct 2016, Porto, Portugal. pp.350-360, 10.1007/978-3-319-45390-3_30. hal-01614595

\author{
HAL Id: hal-01614595 \\ https://hal.inria.fr/hal-01614595
}

Submitted on 11 Oct 2017

HAL is a multi-disciplinary open access archive for the deposit and dissemination of scientific research documents, whether they are published or not. The documents may come from teaching and research institutions in France or abroad, or from public or private research centers.
L'archive ouverte pluridisciplinaire HAL, est destinée au dépôt et à la diffusion de documents scientifiques de niveau recherche, publiés ou non, émanant des établissements d'enseignement et de recherche français ou étrangers, des laboratoires publics ou privés. 


\title{
Competence Matching in Collaborative Consortia for Service-Enhanced Products
}

\author{
Ana Inês Oliveira ${ }^{1}$, Mohammad Shafahi ${ }^{2}$, \\ Hamideh Afsarmanesh ${ }^{2}$, Filipa Ferrada ${ }^{1}$, Luis M. Camarinha-Matos ${ }^{1}$ \\ ${ }^{1}$ Faculty of Sciences and Tecnology, Universidade Nova de Lisboa / Uninova, Portugal \\ ${ }^{2}$ Informatics Institute, University of Amsterdam, The Netherlands \\ aio@uninova.pt,m.shafahi@uva.nl,h.afsarmanesh@uva.nl,faf@uninova.pt, cam@uninova.pt,
}

\begin{abstract}
To exploit new market challenges in manufacturing industries, collaborative environments permit that different stakeholders achieve value creation and differentiated products when addressing the design and development of products that include associated business services (service-enhanced products). In order to facilitate a suitable context for networks of SMEs in the domain of highly customized and service-enhanced products, the GloNet project addressed collaborative networks with different configurations and purposes. In this context, this paper is focused on how a collaborative consortia for serviceenhanced products can be created having into account the requirements for a new product and the necessary normalization of organization's competences.
\end{abstract}

Keywords: Service-Enhanced Product, Collaborative Networks, Specification, Virtual Organization

\section{Introduction}

In manufacturing, to meet customers' demands, the current tendency is to achieve highly customized products. Therefore, the idea of service-enhanced products represents a growing trend due to the fact that consumers more and more demand not only the manufactured products, but also services associated to the physical products. Examples of such services associated to products can be: insurance to protect it, expertise to install it, support to maintain its operation during its life cycle, etc. $[1,2]$. Examples of service-enhanced products are: power plants, intelligent buildings, or complex technical infrastructures. As a consequence, if business services are associated to products in order to create and add value, then certainly that new business or collaboration opportunities can emerge. Hence, to achieve such services it is necessary to consider the involvement and collaboration of several stakeholders organized in collaborative enterprise networks [3]. Nevertheless, one obstacle that organizations typically face when creating a consortium to respond to a new business or collaboration opportunity is how to identify the needed competences to respond to the requirements. To achieve some solutions in this field, the GloNet project [4] (collaborative project funded under the Factories of the Future program of the European Commission) aimed "at designing, developing, and deploying an agile virtual enterprise environment for 
networks of SMEs involved in highly customized and service-enhanced products through end-to-end collaboration with customers and local suppliers".

Prior researches addressed the product specification and design such as collaborative CAD systems [5, 6]. In our previous work the requirements for a product specification system within a Coopetition environment like VBEs and goal oriented VOs [7] and how users can be guided through the specification process [8] were investigated.

In this line, the main challenge that is presented in this paper is twofold: (i) the description of the service-enhanced product specification that considers the customers' requirements and a mapping with existing standards of products classification; and (ii) considering the previous requirements and specification (product goals) with the corresponding mapping of product classification, match it with VBE members' competences to create a consortium. Section 2 briefly summarizes the main outcome of the GloNet project, section 3 responds to the main challenges here presented and, section 3 concludes.

\section{GloNet Approach}

In GloNet, depending on the type of required support and objectives, collaborative networks with different configurations and purposes were addressed. Those networks are summarized in Table 1.

Table 1. GloNet networks

\begin{tabular}{l|l}
\hline Long Term-Strategic Network \\
\hline $\begin{array}{l}\text { Manufacturers } \\
\text { Network }\end{array}$ & $\begin{array}{l}\text { Similar to a virtual organizations breeding environment (VBE), based } \\
\text { on long-term alliances involving: manufacturers, project/product } \\
\text { designers, service providers, and other relevant supporting stakeholders } \\
\text { and entities. }\end{array}$ \\
\hline & $\begin{array}{l}\text { Or "customer related community" - a part form the customer, it also } \\
\text { includes, service providers, and a variety of local support entities. } \\
\text { Although this network might not be fully structured, some principles are } \\
\text { Nhared, such as geographical context, business domain, legal } \\
\text { restrictions, culture, etc. }\end{array}$ \\
\hline Goal-Oriented Network & $\begin{array}{l}\text { Short-term VO related to the design and development of the physical } \\
\text { product and its associated business services. This VO usually ends once }\end{array}$ \\
\hline $\begin{array}{l}\text { Product } \\
\text { the prodopment }\end{array}$ & $\begin{array}{l}\text { Long-term VO with the aim to support the involved stakeholders in the } \\
\text { required business services during the product life-cycle. }\end{array}$ \\
\hline $\begin{array}{l}\text { Product Servicing } \\
\text { Network }\end{array}$ & $\begin{array}{l}\text { Temporary VO with the aim of co-design and co-create innovative } \\
\text { products and/or associated business services. }\end{array}$ \\
\hline $\begin{array}{l}\text { Service Co- } \\
\text { creation Network }\end{array}$
\end{tabular}

For the above networks definitions, the adopted definitions for VBE and VO were:

- "Virtual Organization Breeding Environment (VBE) is an association of organizations and related supporting institutions, adhering to a base long term cooperation agreement, and adopting common operating principles and infrastructures, with the main goal of increasing both 
their chances and preparedness towards collaboration in potential Virtual Organizations" [9, $10]$.

- "Virtual Organization (VO) is a temporary alliance of organizations that come together to share skills or core competences and resources in order to better respond to collaboration opportunities and produce value-added services and products, and whose cooperation is supported by computer networks." [11].

The creation of a new service-enhanced product is therefore performed by a temporary goal-oriented network, in this case a product development network, whose formation is triggered by a new business opportunity brought in by the customer, and eventually found by a broker member of the VBE. The partners of the product development network (VO) are primarily selected from the manufacturers network (VBE) and if needed, additional partners, from the customer related "community" and other stakeholders from the geographical region of the customer, can be added.

The creation of the product development network is prepared inside the manufacturers network. After receiving the product order from the customer the member in charge of all the necessary arrangements for the creation of the VO (i.e. the VO Planner) begins the formation procedure, that: starts with the detailed specification of the product order; continues with the selection of the partners according to their competences against the skills and capacities that are necessary; and ends with the establishment of the necessary agreements and contracts to regulate the VO during its operation phase $[12,13]$. Therefore, the product starts being developed under the supervision of the product development network and this network lasts the necessary time to have the product created.

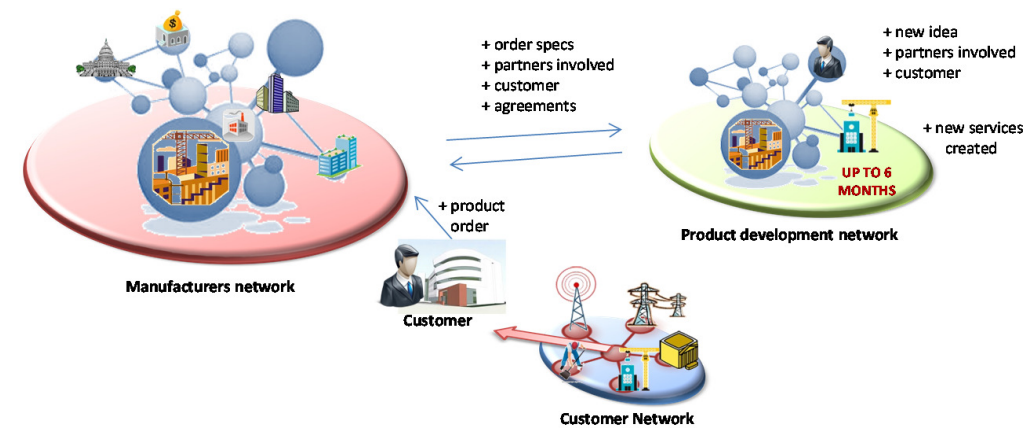

Fig. 1. Interplay of some GloNet networks

Meanwhile, new ideas for new business services might appear. These ideas need to be discussed and brainstormed with some of the product development network partners. Thus, after choosing the most appropriate partners to the mission, a service co-creation network is created. This network (also a VO) has as its main purpose the co-design and co-innovation of novel value-added services to enhance the product being developed by the product development network. Considering that numerous new business concepts may occur, also numerous service co-creation networks might be formed. Once the product and its services are created, the product development network dissolves. Fig. 1 illustrates the interplay among manufacturers' network, customer networks, and product development network. 
The GloNet project developed an ICT support environment system comprising a cloud-based platform supporting various collaboration spaces and a collaborative networking framework that enabling the specifications of service-enhanced products and management of collaborative networks, which gives support to the networks presented before (Fig. 2). The work presented in this paper relies on two core components: the Service-Enhanced Product Support and the Goal-Oriented Networks Management.

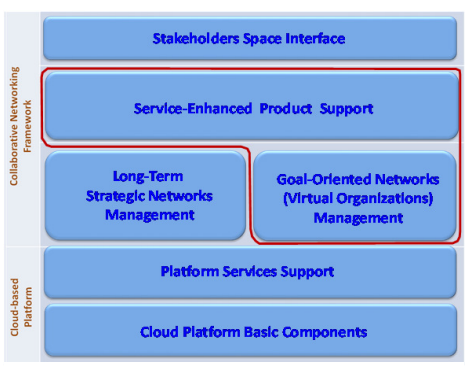

Fig. 2. GloNet system architecture

\section{Matching Competences for Consortia Creation}

One major challenge after the specification and design of a product development network, was how to map the specification of the service-enhanced product order with the corresponding required competences of the partners to be part of the VO. As a response to such challenge, the European standard NACE [14] was adopted as a match with organizations' competences. In this line, three main systems were designed and developed to provide an integrated solution: the VBE Member Management, of the VBE Management system; the Products and Services Specification System; and the VO Formation System.

Fig. 3 , exemplifies the flow of the creation and operation phases of a serviceenhanced product. The creation phase corresponds to a product development network, and the operation and maintenance/monitoring (O\&M) phase corresponds to a product servicing network. The dashed rectangle identifies the interactions of the mentioned three systems, and their description follows.

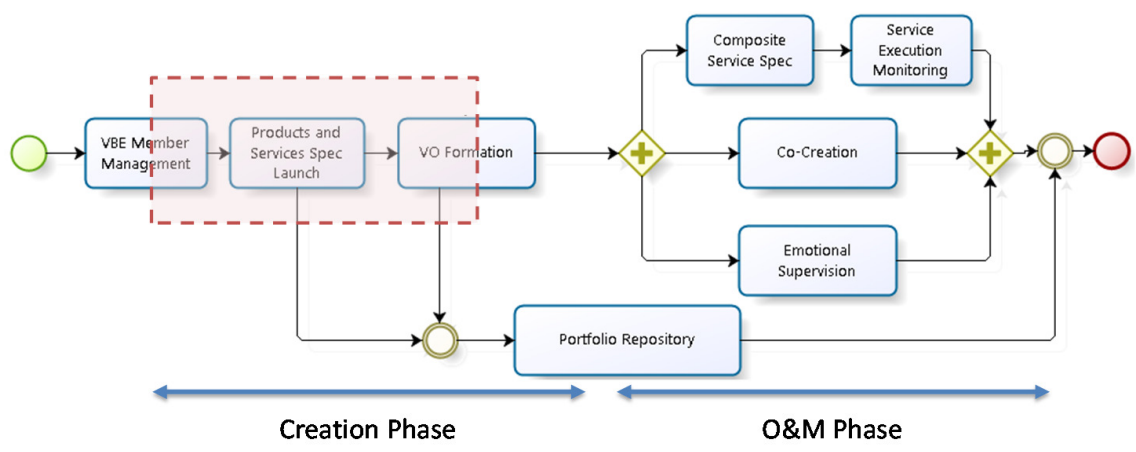

Fig. 3. Flow of the creation and operation \& monitoring phases of a product 


\subsection{VBE Member Management System}

A VBE's main aim is to provide commonality and support for interactions among its members [9]. Moreover, a VBE facilitates the collection and maintenance of members profile data, enabling refined selection criteria usage, comprising levels of trustworthiness, value system, and historical collaboration performance. As such, the establishment of a VBE requires a proper management system that should provide functionalities to manage the members' profiles and VBE's competences, to enable performance management, and to facilitate trust building amongst VBE members. A strategic objective of a VBE is to increase preparedness of each member of the alliance concerning fast configuration of VOs in response to market opportunities.

The VBE members management system is intended to facilitate the VBE administrator with the management of the VBE members. It provides functionalities for VBE member admission and registration in addition to withdrawal. Furthermore, it contains functionalities that VBE members can use to list all other VBE members, and to permit searching for any VBE member and its profile. In both cases, the usage of these functionalities is conditioned by the permissions that the VBE members have. It is considered that the VBE administrator has fully access to all information of VBE members. The VBE members profile management permits the management of the VBE members' profiles. The profile contains a number of defining elements for each individual VBE member (e.g. business domain, name, address, capabilities, skills, etc.) about each VBE member. Moreover, the VBE member competences consists on the main part of the VBE member profile including the latest information related to each VBE member capabilities and capacities, and conspicuous information of their validity, making the VBE members involvement in actions and activities in the VBE eligible, and prepared to $\mathrm{VO}$ creation.

In order to have a common understanding within the VBE, a taxonomy of competences is included, consisting of a hierarchical classification of the competences foreseen for the VBE (i.e. the competences that the VBE would like to fulfill in order to be as competitive as possible in its domain of operation). Each taxonomy class includes a related informal description. To make this taxonomy as broad as possible, the representation of competences is based on the European standard NACE [14, 15].

\subsection{Service-Enhanced Product Specification Tool}

The service-enhanced product specification system supports two main functionalities of product/service specification and product/service registration. This tool is designed and implemented to primarily assist the design \& engineering phase of the serviceenhanced product lifecycle (PLC). Nevertheless, it may also be needed from time to time to specify new sub-products within the operation and maintenance phase of the PLC.

The system facilitates specification of new customer-oriented service-enhanced products, and enables involvement of different stakeholders, e.g. equipment providers as well as the EPC designers. The service-enhanced product specification system primarily captures, handles, and manages the detailed meta-data about the product and all its sub-products/services, and assists users with their specification. The aims of the functionality provided in the product specification system are three-fold. The first goal 
is to support gradual specification of the products. This is needed to reflect the reality of products that are neither defined in one session and nor by one stakeholder. Therefore, detailed specifications that capture and transform customer requirements for a product into discrete sub-product specifications, can be gradually defined by the involved multi-stakeholders, using the developed service-enhanced product specification system. The second goal is to properly capture the classification of all relevant sub-products and enhancing services in a granular and modular manner in the product environment, e.g. distinguishing and capturing both the electrical and mechanical aspects of a sub-product. This will in turn support effective multiperspective retrieval/discovery of information related to sub-products, as well as creating their concise presentation, needed for common understanding among different related stakeholders. The third goal is to capture all the details related to sub-products in a reusable from. As such, the existing specifications of already introduced subproducts can be either fully or partially (e.g. at the level of certain detailed feature-kind) be reused for the specification of other sub-products. Fig. 4 demonstrates the overall flow for the specification process for complex products.

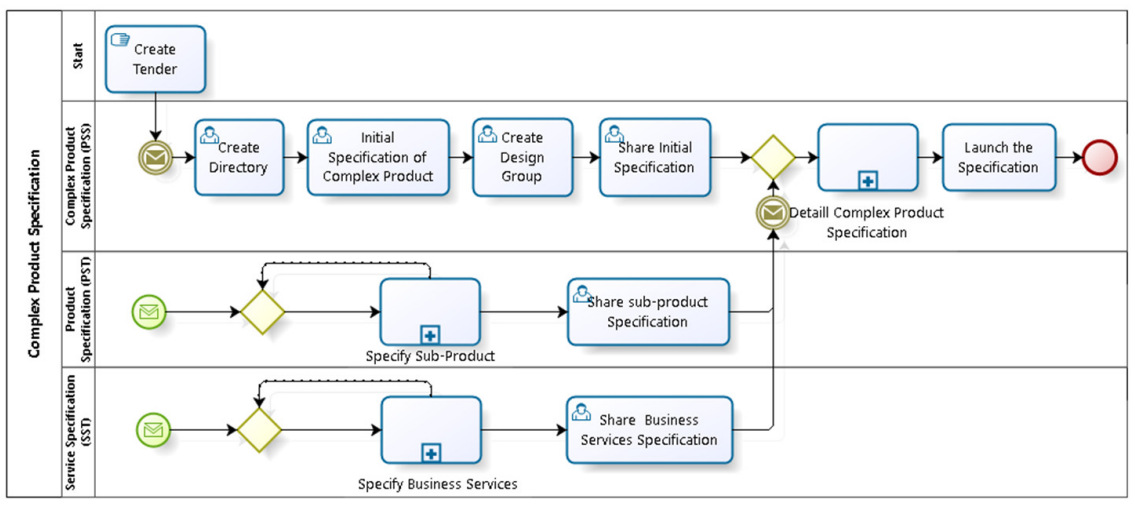

Fig. 4. Flow of the complex product specification

Other than the above mentioned functionalities sub-products specified using the product specification system are semi-automatically classified using the PRODCOM [16] convention for classifications, that are pre-defined in the system. The choice of PRODCOM suits this case because it is an extension of the CPA and as such compatible with NACE [14]. Furthermore, PRODCOM itself is accepted within the EU as a standard extendable coding system. The NACE Rev. 2 coding system, as suggested by its description of "Statistical Classification of Economic Activities in the European Community", classifies the economical activities preformed to realize a product or service. This provides valuable input when a specification is being realized by the VO formation sub-system and organizations need to be selected for the VO. A PRODCOM code is constructed by further extending the NACE activity code, and therefore embeds in itself the activity that is preformed to realize the product. If a product class is associated with at least one PRODCOM code, we can then use this coding in order to find suitable organizations that can realize this product class by focusing on the NACE 
part of the PRODCOM code and looking for organizations that have announced this NACE code as one competence.

\subsection{Mapping of Service-Enhanced Product's Specification and Organizations Competences}

As suggested before, the recommendation of a set of organizations that can produce or support a certain class of products can be achieved by looking at the NACE code of their competences, when related to the PRODCOM code of the product. If the class of some product is not directly associated with a PRODCOM code, then sub-products of the product can be used, were their classes are coded with PRODCOM, so that the competence of organizations standardized through the NACE [14, 15] coding convention can be used to build the link to that product. As such interlinking the subproducts of the product with the competences required from organizations to realize the sub-product, are established. As an example, the PRODCOM code "C27.11.43.80" refers to "Transformers, n.e.c., having a power handling capacity $>500 \mathrm{kVA}$ " and its respective NACE code of "C27.11" refers to: "Manufacturing of electric motors, generators, transformers and electricity distribution and control apparatus". Now if a sub-product for instance is associated with this PRODCOM code "C27.11.43.80", then the suitable organizations that can realize and/or support this product can be identified by taking the NACE part of this PRODCOM coding which is "C27.11", and then looking for those organizations who have defined the NACE code "C27.11" as one of their competences.

The above mechanism enables our system to recommend a set of organizations capable of realizing and supporting a complex product. The approach suggested by Resnik [17] was used in order to further rank the suitability of a NACE code used as organization competency for realizing a product associated with a PRODCOM code. Clearly in the case when a product is associated with more than one PRODCOM code, and the organizations are associated with more than one competence (i.e. NACE codes), which is rather a typical case, then the most overlap between the interlinked NACE and PRODCOM codes are desired, in other words the more matches between an organizations set of competencies and the PRODCOM codes defined for a product, the more that organization is suited for realizing and support that product. Such a large number of matches in fact indicate that the sub-product and the organization belong to the same sector.

\subsection{Consortia Creation}

The formation of the VO for service-enhanced product development mostly involves the plan and scheduling of the work order consistent with the service-enhanced product specification, and selecting the appropriated partners considering the existent VBE competences. Nevertheless, to finish the VO formation, and assist the VO partners in attaining agreements, negotiation functionalities are also essential [13]. The VO agreements will serve as foundations for the VO governing principles through its operation phase [12]. Fig. 5 exemplifies the main flow of the VO formation process. Nevertheless, as the focus of this work is on competences for consortia creation, this 
section highlights the three first services: New order characterization, VBE members competences analysis, and Potential VOs assemblage.

As such, important services in the VO formation are:

New Order Characterization: to assist the VO planner in the characterization of the new order for products or/and services. Considering the identified requirements of the new order, the characterization relies on the decomposition of the new order into goals considering the outcome of the product specification tool and the VBE competences taxonomy.

VBE Members Competences Analysis: to support the VO planner in searching for the suitable partners for the VO. It allows checking how the New Order Characterization goals can be fulfilled considering the existing competences of the VBE members. Thus, the VO planner can properly detect the appropriated partners for the VO being created. The members are therefore searched within the VBE, the customer network, and also other relevant local entities or suppliers related with the VBE.

Potential VOs Assemblage: to assist the VO planner in making the conceivable consortia compositions considering the information already provided by the New Order Characterization and the VBE Members Competences Analysis. In this step, the VO planner already has a list containing the potential partners that can deliver, or are able to complete, the defined goals.

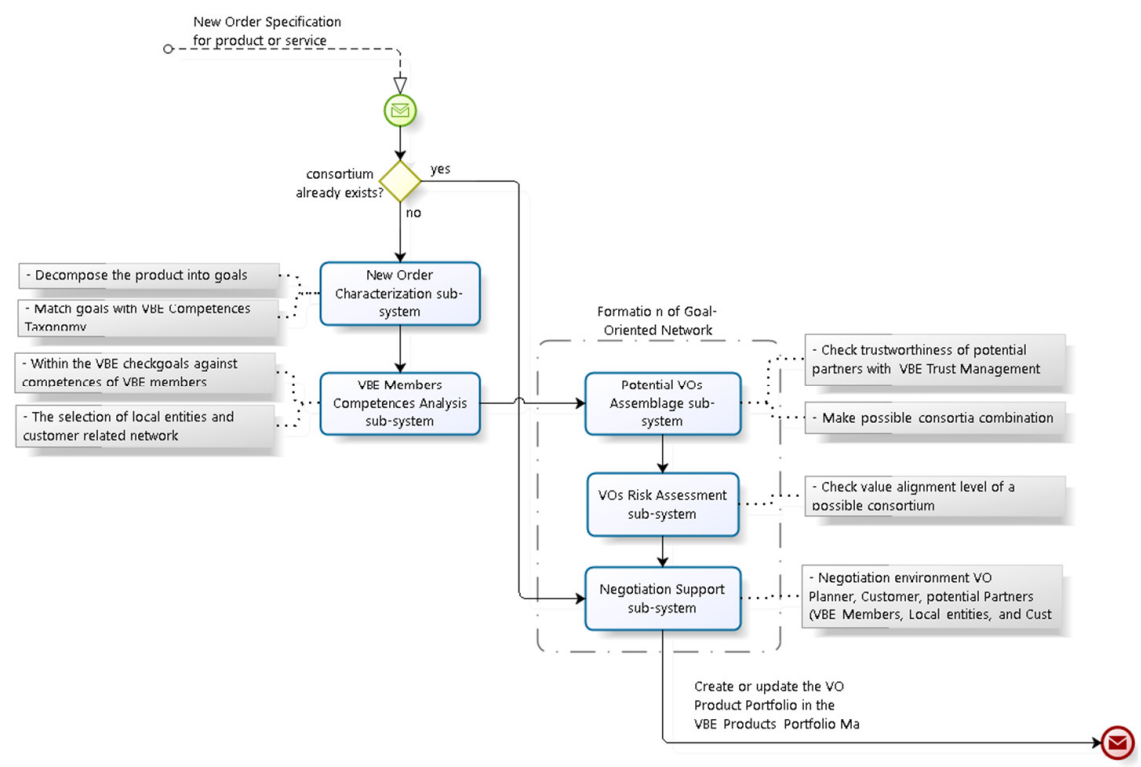

Fig. 5. Main flow of the VO formation process

Moreover, the VO planner can make a VO risk assessment [18] using other VBE functionalities (such as evaluate the trustworthiness levels of partners [19], and their value systems alignment [20]). As mentioned, to finalize the VO formation, the VO 
planner starts the negotiation process [13] to achieve agreements among VO partners, and launch the VO.

\section{Conclusions}

One of the aims of the GloNet project was the design, development, and deploy of an agile enterprise environment for networks of SMEs involved in highly customized and service-enhanced products through collaboration with customers and local suppliers. One of the achievements was the specification of configurations and purposes of collaborative networks: product development network, service co-creation network, product servicing network, manufacturers' network, and customer network. This paper addresses the creation of a product development network focusing on three systems that were developed to permit its support, namely: the VBE Member Management, of the VBE Management system; the Products and Services Specification System; and the VO Formation System. The interaction of these three systems considered the normalization of the requirements of a new product and the necessary competences of organizations. Therefore, the challenges of addressing: $(i)$ the service-enhanced product specification, mapping it with existing standards; and (ii) the consortium creation focusing on the VBE members matching, were achieved.

The approach was validated in the scope of the GloNet project, in a solar industry and intelligent buildings networks. As a general result, the solution was positively validated in terms of developed models and prototypes. Nevertheless, when evolving to commercial products, some improvements shall be considered, namely in terms of user interfaces.

Acknowledgments. This work was funded in part by the European Commission through the GloNet project (FP7 programme). The authors also thank the contributions from their partners in this project. Partial support also comes from Fundação para a Ciência e Tecnologia through the PEST program UID/EEA/00066/2013.

\section{References}

[1] Shen, Q. Research on organization mode selection of service-enhanced manufacturing enterprise. in 3rd International Conference on Information Management, Innovation Management and Industrial Engineering (ICIII). 2010. Kunming, China: IEEE.

[2] Bitner, M.J. and Brown, S.W., The evolution and discovery of services science in business schools, in Services Science, B. Stauss , et al., Editors. 2008, Springer. p. 91-101.

[3] Camarinha-Matos, L.M., Afsarmanesh, H., Oliveira, A.I., and Ferrada, F., Cloud-Based Collaborative Business Services Provision, in Enterprise Information Systems, Lecture Notes in Business Information Processing, S. Hammoudi, et al., Editors. 2014, Springer. p. 366-384.

[4] GloNet. GloNet, Glocal Enterprise Network Focusing on Customer-Centric Collaboration. 2011-2015 last access: 15.10.2015]; Available from: http://www.glonet-fines.eu/.

[5] Li, W.D., Fuh, J.Y., and Wong, Y.S., An Internet-enabled integrated system for co-design and concurrent engineering. Computers in Industry, 2004. 55(1): p. 87-103.

[6] Li, W.D., Lu, W.F., Fuh, J.Y., and Wong, Y.S., Collaborative computer-aided design research and development status. Computer-Aided Design, 2005. 37(9): p. 931-940. 
[7] Shafahi, M., Afsarmanesh, H., and Sargolzaei, M., A Coopetition Space for Complex Product Specification, in Collaborative Systems for Smart Networked Environments. 2014, Springer Berlin Heidelberg. p. 83-97.

[8] Afsarmanesh, H., Shafahi, M., and Sargolzaei, M., On service-enhanced product recommendation guiding users through complex product specification, in International Conference on Computing and Communications Technologies (ICCCT). 2015, IEEE. p. 43-48.

[9] Afsarmanesh, H., Camarinha-Matos, L.M., and Ermilova, E., VBE reference framework. In: Methods and tools for collaborative networked organizations, L.M. Camarinha-Matos, H. Afasarmanesh, and M. Ollus, Editors. 2008, Springer. p. 35-68.

[10] Msanjila, S.S. and Afsarmanesh, H., A multi-model approach to analyze interorganizational trust in VBEs, in Collaborative Networks: Reference Modeling, L.M. Camarinha-Matos and H. Afsarmanesh, Editors. 2008, Springer. p. 195-214.

[11] Camarinha-Matos, L.M., Afsarmanesh, H., and Ollus, M., ECOLEAD: A Holistic Approach to Creation and Management of Dynamic Virtual Organizations. In: Collaborative Networks and Their Breeding Environments, L.M. Camarinha-Matos, H. Afasarmanesh, and A. Ortiz, Editors. 2005, Springer US. p. 3-16.

[12] Oliveira, A.I. and Camarinha-Matos, L.M., Negotiation and Contracting in Collaborative Networks. In: Emerging Trends in Technological Innovation, L.M. Camarinha-Matos, P. Pereira, and L. Ribeiro, Editors. 2010, Springer. p. 83-92.

[13] Oliveira, A.I. and Camarinha-Matos, L.M., Electronic Negotiation Support Environment in Collaborative Networks. In: Technological Innovation for Value Creation, L.M. Camarinha-Matos, E. Shahamatni, and G. Nunes, Editors. 2012, Springer. p. 21-32.

[14] EurLex. Regulation (EC) No 1893/2006 of the European Parliament and of the Council of 20 December 2006 establishing the statistical classification of economic activities NACE Revision 2 and amending Council Regulation (EEC) No 3037/90 as well as certain EC Regulations on specific statistical domains. Last access: 27.04.2016]; Available from: http://eur-lex.europa.eu/legal-content/EN/TXT/?uri=CELEX:32006R1893.

[15] Eurostat. NACE Rev. 2 - Statistical classification of economic activities. Last access: 27.04.2016]; Available from: http://ec.europa.eu/eurostat/en/web/products-manuals-andguidelines/-/KS-RA-07-015.

[16] Eurostat. Your key to European statistics. Last access: 28.04.2016]; Available from: http://ec.europa.eu/eurostat/web/prodcom.

[17] Resnik, P., Semantic similarity in a taxonomy: An information-based measure and its application to problems of ambiguity in natural language. J. Artif. Intell. Res.(JAIR), 1999. 11: p. 95-130.

[18] Oliveira, A.I. and Camarinha-Matos, L.M., Negotiation support and risk reduction in collaborative networks. In: Technological Innovation for the Internet of Things, L.M. Camarinha-Matos, S. Tomic, and P. Graça, Editors. 2013, Springer. p. 15-24.

[19] Msanjila, S. and Afsarmanesh, H., Trust analysis and assessment in virtual organization breeding environments. International Journal of Production Research, 2008. 46(5): p. 12531295.

[20] Macedo, P. and Camarinha-Matos, L.M., A qualitative approach to assess the alignment of Value Systems in collaborative enterprises networks. Computers \& Industrial Engineering, 2013. 64(1): p. 412-424 